\title{
Optimal drying conditions for valorization of industrial apple pomace: Potential source of food bioactive compounds
}

\author{
FARAJA DEO GONELIMALI* (D), BEATRIX SZABÓ-NÓTIN and \\ MÓNIKA MÁTÉ
}

Department of Vegetable and Fruit Processing Technology, Institute of Food Science and Technology, Hungarian University of Agriculture and Life Sciences, Hungary

\section{CONFERENCE FULL PAPER}

Received: June 8, $2021 \bullet$ Accepted: August 3, 2021

Published online: August 19, 2021

(C) 2021 The Author(s)

\begin{abstract}
Apple pomace contains a large amount of useful bioactive compounds that have wide application in the food industry. In this study the effect of drying temperature and pressure (high temperature $80{ }^{\circ} \mathrm{C}$ and low temperature $60^{\circ} \mathrm{C}$ using a conventional oven and a combination of conventional plus vacuum drying oven) on the antioxidant capacity and phenolic compounds of apple pomace extract was investigated. For a combination of conventional and vacuum drying ovens, samples were first dried by a conventional oven to a moisture content of approximately $10 \%$ then vacuum dried to reach a final moisture content of $3-4 \%$. After the drying processes, ethanolic extraction was performed and the amount of total polyphenol and the antioxidant capacity (FRAP) were evaluated to determine a best drying method. The drying curves were also determined. The drying temperature affects the duration of the drying, the rate of water loss, and the remaining amount of antioxidant compounds.
\end{abstract}

\section{KEYWORDS}

apple pomace, antioxidant activity, total phenolic content, water activity, moisture content

*Corresponding author. E-mail: fgonelimali@gmail.com 


\section{INTRODUCTION}

Waste from processing of agricultural products can be an important source of cheap and reliable raw materials for obtaining bioactive compounds that can be used as natural food additives (Arshad and Batool, 2017). Every year, tons of agricultural industrial wastes are produced from food processing industries. In most cases, these wastes are thrown away to the environment, some are being burnt and recently, a small portion are being used to produce various products such as animal feed, biofuel, pharmaceuticals and food additives (Sadh et al., 2018). One of the important agro industrial wastes that can have application in the development of natural food additives are apple pomace. Apple pomace are the solid waste products from processing of apples into juice, wine and cider. They include skin, seeds, stem and flesh tissues left after obtaining the juice from squeezing the apples. About 25\% of an apple's composition and weight is the pomace. Thus, for every amount of the apples that are processed, an estimate of $25 \%$ is waste, and most of these are thrown away to the environment, however, there are attempts to utilize them as animal feed ingredients. Recently, it has been proved that these substances contain huge amount of bioactive compounds especially pectin and polyphenols (Cao et al., 2009; Kolodziejczyk et al., 2009; Virot et al., 2010; Bodor et al., 2020; Zin et al. 2020). Being rich in bioactive compounds, particularly pectin and polyphenols, extracts of the apple pomace have a potential to be used as green food additives. Pectin from apple pomace have been used as thickening and gelling agents in formulation of various food products (Lyu et al., 2020). Similarly, polyphenols from the pomace have also been used to enhance antioxidant activity in production of functional foods that can help to fight inflammation and cancer diseases. In addition to that, extracts from apple pomace have a potential to be used as natural food preservatives due to their antimicrobial activity. In order to properly obtain these bioactive compounds, proper handling of the pomace immediately after being produced is very important. One of the key steps in early handling of the pomace is drying.

Drying of the pomace is an essential process in order to remove excess water that can cause spoilage prior to its utilization. Usually, fresh apple pomace contain high moisture content and water activity, about $70 \%$ and 0.84 respectively. These conditions are ideal for the growth of microorganisms especially fungi that can lead to spoilage and production of toxins. Moreover, drying facilitates proper storage since less space and storage materials are required to store dried pomace as compared to fresh pomace. In addition to that, drying of the pomace is an important technical step that is required during extraction process where most of the bioactive compounds are extracted better on dried pomace rather than fresh (Jung et al., 2015). In order to protect important bioactive compounds from degradation, attention to proper drying methods should be under consideration.

Several drying methods such as traditional sun drying, solar driers, conventional ovens and microwave driers can be employed singular or in combination for the drying of apple pomace. Considering the effect of the drying method to the quality of the resulting bioactive compounds, energy and cost as well as time, there is a need to properly investigate and optimize different drying conditions that can lead to extracts with high functional properties.

\section{MATERIALS AND METHODS}

Apple pomace from industrial juice production were obtained from Agrana Juice Ltd (Hungary). 
Drying using the conventional oven (LP 232/1, Hungary), $200 \mathrm{~g}$ of the pomace were spread in a drying tray with a depth of $0.5 \mathrm{~cm}$. Trays were then taken to the oven and dried at $60{ }^{\circ} \mathrm{C}$ and $80{ }^{\circ} \mathrm{C}$ and the moisture content was being monitored every hour. For a vacuum oven drying, samples were first dried by a conventional oven to a moisture content of about 10 percent at $80{ }^{\circ} \mathrm{C}$ and $60{ }^{\circ} \mathrm{C}$. Thereafter, samples were dried in the vacuum dryer at a temperature of $60{ }^{\circ} \mathrm{C}$ and a pressure of 65 mbar, moisture content was monitored every hour until it reached 3-4\%. Dried samples were ground into fine powder using a "PRINCESS" multi chopper grinder and were vacuum packaged till the day of extraction. Determination of dry material content was performed by using a MAC-50 rapid moisture analyzer (Radwag Waagen GMBH, Hilden, Germany). To determine the water activity, Novasina, LabMaster-aw equipment was used. Percentage recovery of the dried sample was obtained by the following formula:

$$
\operatorname{Recovery}(\%)=(\text { Final weight }(g) \div \text { Intial weight }(g)) \times 100
$$

where, final weight is the weight of the sample after drying and initial weight is the weight of the sample before drying.

Ultrasound assisted extraction was performed as the following: briefly, $15 \mathrm{~g}$ of the pomace were mixed with $450 \mathrm{ml}$ of $80 \%$ ethanol $(1: 30 \mathrm{w} / \mathrm{v})$ in a flask. Thereafter the flasks were placed in the sonication bath, $35 \mathrm{kHz}$ for $1 \mathrm{~h}$ (Bandelin, RK 52). Obtained solution was filtered using Whatman filter paper No.1, using vacuum pump. Solvent from the obtained filtrate was removed using rotary evaporator (IKA, Model: RW 10C S99) and further removed on circulating air oven $\left(60^{\circ} \mathrm{C}\right)$ in petri dishes. Weight of the obtained extracts was determined and diluted accordingly with distilled water to obtain a final extract solution with a concentration of $200 \mathrm{mg} \mathrm{mL}^{-1}$.

Total phenolics were determined according to the Folin-Ciocalteu colorimetric method as described by Singleton and Rossi (1965). Briefly, 1,250 $\mu \mathrm{L}$ of Folin solution (1:10 v/v Folin; distilled water) was added in the test tube followed by addition of $150 \mu \mathrm{L}$ of methanol $(4: 1 \mathrm{v} / \mathrm{v}$ methanol; distilled water). Then, $100 \mu \mathrm{L}$ of the sample was added and the solution was allowed to stand for $1 \mathrm{~min}$, followed by the addition of $1,000 \mu \mathrm{L}$ of sodium carbonate solution.

Antioxidant capacity was determined using Ferric Reducing Ability of Plasma (FRAP) assay (Benzie and Strain, 1996). Producing FRAP reagent were used acetate buffer ( $\mathrm{pH}$ 3.6), 2,4,6tripyridyl-s-triazine (TPTZ) solution, and $\mathrm{FeCl}_{3} \times 6 \mathrm{H}_{2} \mathrm{O}$ solution. The reagent and samples were added to each well and mixed thoroughly. The absorbance was taken at $593 \mathrm{~nm}$ after $5 \mathrm{~min}$. Results were expressed in ascorbic acid equivalent (mg ascorbic acid/mL extract) using an ascorbic acid standard calibration curve. Color was determined according to C.I.E.LAB system using a tristimulus colorimeter (Konica Minolta CR 410, Minolta Canada Inc.). Concentration of water soluble sugars (Brix percentage) was determined using a digital refractometer (ATAGO DBX-55).

Statistical analysis was performed by one factor complete randomized ANOVA using IBM SPSS software version 25 .

\section{RESULTS AND DISCUSSION}

The data of fresh apple pomace drying using atmospheric oven at different temperatures and atmospheric oven combined vacuum oven are shown in Fig. 1. Depending on operational 


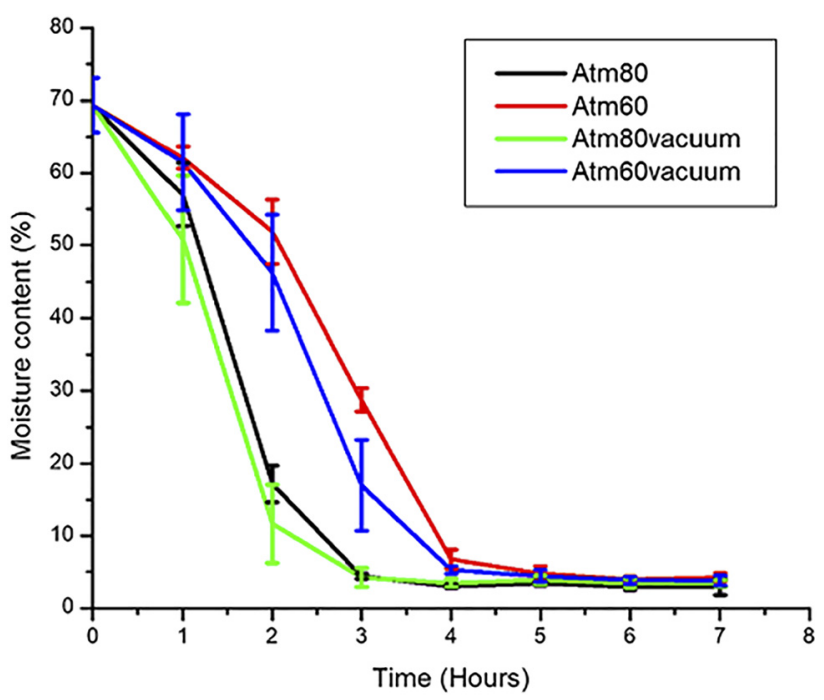

Fig. 1. Decrease of moisture content during drying of the apple pomace. Error bars indicate the corresponding standard deviations. Atm 80 and Atm60 stand for drying the pomace at 80 and 60 using conventional atmospheric oven respectively. Atm 80 vacuum and Atm60 vacuum represent drying the pomace at $80{ }^{\circ} \mathrm{C}$ conventional oven plus vacuum drying and $60{ }^{\circ} \mathrm{C}$ conventional oven plus vacuum drying respectively

conditions (atmospheric or vacuum), air velocity $(1-2 \mathrm{~m} / \mathrm{s})$, temperature $\left(60-105^{\circ} \mathrm{C}\right)$, and amount of sample apple pomace drying takes 3-10 h (Wang et al., 2007). Raw apple pomace had an initial moisture content of $69 \%$, and drying procedure was continued till the moisture content of the sample reached final wet content $(2.94-4.28 \% ; 3$ and $6 \mathrm{~h}$ ) (Table 1 ). In the case of atmospheric drying at $80{ }^{\circ} \mathrm{C}$ during the first $2 \mathrm{~h}$ (to $11.67-17.17 \%$ ) the moisture content of apple pomace decreased quickly, after that, the moisture content decreased slightly.

Table 1 shows time required to dry the samples, moisture content of the dried samples, and the percentage recovery of the pomace using a conventional oven and a combination of a conventional oven with vacuum drying to reach a moisture content of approximately $4 \%$. The final weight was the highest in the case of using $60{ }^{\circ} \mathrm{C}$ atmospheric drying, and the smallest weight was obtained in the case of $80{ }^{\circ} \mathrm{C}$ atm + vacuum drying method. The recovery shows similar tendency. The highest recovery $\%$ was achieved using $60{ }^{\circ} \mathrm{C}$ atmospheric drying, and the smallest recovery was in the case of $80{ }^{\circ} \mathrm{C}$ atm + vacuum drying method.

Table 1. Time, final weight and recovery of the pomace using different drying method

\begin{tabular}{lcccc}
\hline Drying method & $80{ }^{\circ} \mathrm{C}$ atm. & $60{ }^{\circ} \mathrm{C}$ atm. & $\begin{array}{c}80{ }^{\circ} \mathrm{C} \text { atm. }+ \\
\text { Vacuum }\end{array}$ & $\begin{array}{c}60{ }^{\circ} \mathrm{C} \text { atm. }+ \\
\text { Vacuum }\end{array}$ \\
\hline Time (hours) & 3 & 6 & 3 & 6 \\
Final moisture content $\pm \mathrm{SE}$ & $2.94 \pm 0.64^{\mathrm{a}}$ & $4.28 \pm 0.32^{\mathrm{a}}$ & $3.42 \pm 0.19^{\mathrm{a}}$ & $3.82 \pm 0.06^{\mathrm{a}}$ \\
Recovery $(\%) \pm \mathrm{SE}$ & $20.96 \pm 0.70^{\mathrm{a}}$ & $22.63 \pm 0.36^{\mathrm{a}}$ & $19.99 \pm 0.82^{\mathrm{a}}$ & $20.49 \pm 0.68^{\mathrm{a}}$ \\
\hline
\end{tabular}


After extraction method, the water soluble sugars of the extracts were between 13.77 and $15.81 \%$. According to the ANOVA results, the drying method had significant effect on water soluble sugars $(P<0.001)$.

Table 2 shows the color values in the case of extracts. $L^{*}$ defines the lightness of the pomace extracts, in the case of using Atm $80{ }^{\circ} \mathrm{C}+$ vac. drying method, the $\mathrm{L}^{*}$ value is smaller than in the other three cases. In the case of $\mathrm{a}^{*}$ values (green-red opponent colors, with negative values toward green and positive values toward red), were in the range of -0.99 to +0.6 .

The $b^{*}$ values (blue-yellow opponents, with negative numbers toward blue and positive toward yellow) were between 22.47 and 24.36. There is similar increasing tendency as in the case of $L^{*}$ values. The effect of drying method on the color values of the extracts was evaluated by one-way analysis of variance (ANOVA). The drying method had no significant effect on color values of the extracts $(P=0.31),(P=0.07)$ and $(P=0.177)$ for $\mathrm{L}^{*}, \mathrm{a}^{*}$ and $\mathrm{b}^{*}$ respectively.

Table 3 contains the total phenolic content (TPC) of the apple pomace extracts. The TPC of the final apple pomace extract was the highest $\left(1,075 \mu \mathrm{g} \mathrm{mL}^{-1}\right)$ in the case of atmospheric drying at $80^{\circ} \mathrm{C}+$ vacuum drying, and was lower when atmospheric $60^{\circ} \mathrm{C}$ and vacuum drying methods were used (at $60{ }^{\circ} \mathrm{C}$ atm + vacuum $874 \mu \mathrm{g} \mathrm{mL}{ }^{-1}$. The effect of drying method and the TPC content of the extracts was evaluated by one-way analysis of variance (ANOVA). The drying method had significant effect on TPC content of the extracts ( $P$ value at 95\% confidence: 0.043 ).

Madrau et al. (2007) obtained similar tendency. They vacuum dried apricot at 55 and $75{ }^{\circ} \mathrm{C}$ and apricots dried at $75^{\circ} \mathrm{C}$ had a significantly higher phenolic composition than those dried at $55^{\circ} \mathrm{C}$.

Zielińska and Michalska-Ciechanowska (2016) dried blueberries using hot air convective drying, microwave vacuum drying, and their combination. The highest content of total polyphenols was noted after hot air convective drying at $90^{\circ} \mathrm{C}$. Lower air temperature and prolonged exposure to oxygen resulted in greater degradation of polyphenols.

Decreasing of polyphenols could be due to several factors, such as increased antioxidant power of polyphenols at an intermediate state of oxidation, increase in reducing sugar and formation of Maillard Reaction Products.

Table 4 shows the antioxidant capacity of the apple pomace extract expressed in ascorbic acid equivalent ( $\mu \mathrm{g}$ ascorbic acid/mL extract). The highest antioxidant capacity was measured when the sample was dried at $60{ }^{\circ} \mathrm{C}$ atmospheric, and the lowest value was determined in the

Table 2. Color values of the extracts

\begin{tabular}{lcccc}
\hline & Atm_80 & Atm_60 & Atm_80_vac & Atm_60_vac \\
\hline $\mathrm{L}^{*} \pm \mathrm{SE}$ & $44.68 \pm 1.52^{\mathrm{a}}$ & $42.37 \pm 1.26^{\mathrm{a}}$ & $40.02 \pm 2.01^{\mathrm{a}}$ & $44.32 \pm 2.24^{\mathrm{a}}$ \\
$\mathrm{a}^{\star} \pm \mathrm{SE}$ & $-0.70 \pm 0.48^{\mathrm{a}}$ & $-0.77 \pm 0.13^{\mathrm{a}}$ & $0.6 \pm 0.32^{\mathrm{a}}$ & $-0.99 \pm 0.50^{\mathrm{a}}$ \\
$\mathrm{b}^{*} \pm \mathrm{SE}$ & $26.72 \pm 1.15^{\mathrm{a}}$ & $24.01 \pm 0.77^{\mathrm{a}}$ & $22.47 \pm 1.42^{\mathrm{a}}$ & $24.36 \pm 1.38^{\mathrm{a}}$ \\
\hline
\end{tabular}

Superscript letters indicate significance difference.

Table 3. TPC content of the extract ( $\mu \mathrm{g} \mathrm{mL}{ }^{-1}$ extract)

\begin{tabular}{ccccc}
\hline & Atm_80 & Atm_60 & Atm_80_vac & Atm_60_vac \\
\hline TPC \pm SE & $1,000 \pm 75.27^{\mathrm{a}, \mathrm{b}}$ & $944 \pm 43.00^{\mathrm{a}, \mathrm{b}}$ & $1,075 \pm 32.26^{\mathrm{b}}$ & $874 \pm 19.06^{\mathrm{a}}$ \\
\hline
\end{tabular}


Table 4. FRAP values of the extract ( $\mu \mathrm{g} \mathrm{AS} \mathrm{mL}^{-1}$ extract)

\begin{tabular}{ccccc}
\hline & Atm_80 & Atm_60 & Atm_80_vac & Atm_60_vac \\
\hline FRAP value \pm SE & $471 \pm 9.32^{\mathrm{a}}$ & $744 \pm 23.18^{\mathrm{c}}$ & $576 \pm 9.18^{\mathrm{a}, \mathrm{b}}$ & $588 \pm 47.32^{\mathrm{b}}$ \\
\hline
\end{tabular}

Superscript letters indicate significant differences among the test groups.

case of drying the sample at $80{ }^{\circ} \mathrm{C}$ atmospheric. Between atmospheric $80{ }^{\circ} \mathrm{C}+$ vacuum and atmospheric $60{ }^{\circ} \mathrm{C}+$ vacuum there was no significant difference. According to the statistical analysis, drying method has significant effect on the antioxidant capacity ( $P$ values at $95 \%$ confidence $<0.001$ ).

\section{CONCLUSION}

Industrial apple pomace is a good source of bioactive compounds, particularly phenolic compounds that have antioxidant activity. This is because it is in abundance, easily obtained and cheap from an economic point of view. Our results show that during processing of the pomace, drying conditions are of great importance since they can affect composition (phenolic content) and function (antioxidant activity) of the pomace. Based on our results, drying apple pomace at $60{ }^{\circ} \mathrm{C}$ using conventional atmospheric oven results in significantly higher antioxidant activity compared to other methods that have been investigated in this study. Further purification of the apple pomace extracts, identification of phenolic fractions and examination of their stability are necessary to be studied further. Apple pomace should be regarded as a valuable product and a functional food ingredient that has a potential to produce functional foods such as those with natural antioxidants, particularly jams, juices and biscuits.

\section{ACKNOWLEDGMENT}

This work was supported by EFOP-3.6.3-VEKOP-16-2017-00005.

The authors acknowledge the Hungarian University of Agriculture and Life Science's Doctoral School of Food Science for the support in this study.

\section{REFERENCES}

Arshad, M.S. and Batool, S.A. (2017). Natural antimicrobials, their sources and food safety. In: Karunaratne, D.N. (Ed.), Food additives. Intech Open, London, pp. 87-102. Available from: http://dx.doi.org/10. 5772/intechopen.70197.

Benzie, I.I.F. and Strain, J.J. (1996). The ferric reducing ability of plasma (FRAP) as a measuring of "antioxidant power". The FRAP assay. Analytical Biochemistry, 239: 70-76.

Bodor, Zs., Pergel, B., and Benedek, Cs. (2020). Impact of heat treatment and flavorings on the antioxidant capacity of black and green tea. Progress in Agricultural Engineering Sciences, 16(S2): 55-63. https://doi. org/10.1556/446.2020.20007. 
Cao, X., Wang, C., Pei, H., and Sun, B. (2009). Separation and identification of polyphenols in apple pomace by high-speed counter current chromatography and high-performance liquid chromatography coupled with mass spectrometry. Journal of Chromatography A, 1216(19): 4268-4274.

Jung. J., Cavender, G., and Zhao, Y. (2015). Impingement drying for preparing dried apple pomace flour and its fortification in bakery and meat products. Journal of Food Science and Technology, 52(9): 55685578 .

Kolodziejczyk, K., Kosmala, M., Milala, J., Sójka, M., Uczciwek, M., Król, B., Markowski, J., and Renard, C.M.G.C. (2009). Characterisation of the chemical composition of scab resistant apple pomace. Journal of Horticultural Science and Biotechnology, 84: 89-95.

Lyu, F., Luiz, S.F., Denise, D.R.P., Cruz. A.D., Ajlouni, S., and Ranadheera, C.H. (2020). Apple Pomace as a functional and healthy ingredient in food products: a review. Processes, 8(3): 319; https://doi.org/10. 3390/pr8030319.

Madrau, M., Piscopo, A., Sanguinetti, A., Del Caro, A., Poiana, M., Romeo, F.V., and Piga, A. (2007). Effect of drying temperature on polyphenolic content and antioxidant activity of apricots. European Food Research and Technology, 228: 441-448.

Sadh, P.K., Duhan, S., and Duhan, J.S. (2018). Agro-industrial wastes and their utilization using solid state fermentation: a review. Bioresources and Bioprocessing, 5: 1. https://doi.org/10.1186/s40643-017-0187-z.

Singleton, V.L. and Rossi, J.A. (1965). Colorimetry of total phenolics with phosphomolybdic phosphotungstic acid "reagents". American Journal of Enology and Viticulture, 16: 144-158.

Virot, M., Tomao, V., Le Bourvellec, C., Renard, C.M., and Chemat, F. (2010). Towards the industrial production of antioxidants from food processing by-products with ultrasound-assisted extraction. Ultrasonics Sonochemistry, 17(6): 1066-1074.

Wang, Z., Sun, J., Liao, X., Chen, F., Zhao, G., Wu, J., and Hu, X. (2007). Mathematical modeling on hot air drying of thin layer apple pomace. Food Research International, 40(1): 39-46.

Zielińska, M. and Michalska-Ciechanowska, A. (2016). Microwave-assisted drying of blueberry (Vaccinium corymbosum L.) fruits: drying kinetics, polyphenols, anthocyanins, antioxidant capacity, colour and texture. Food Chemistry, 212. https://doi.org/10.1016/j.foodchem.2016.06.003.

Zin, M.M., Borda, F., Márki, E., and Bánvölgyi, Sz. (2020). Betalains, total polyphenols, and antioxidant contents in red beetroot peel (Cylindra type). Progress in Agricultural Engineering Sciences, 16(S2): 2736. https://doi.org/10.1556/446.2020.20004.

Open Access. This is an open-access article distributed under the terms of the Creative Commons Attribution 4.0 International License (https://creativecommons.org/licenses/by/4.0/), which permits unrestricted use, distribution, and reproduction in any medium, provided the original author and source are credited, a link to the CC License is provided, and changes - if any - are indicated. (SID_1) 